\title{
Practicing community geography in times of crisis
}

\author{
Jerry Shannon - Hannah Torres • Kathryn A. Mariner • Timothy L. Hawthorne
}

Accepted: 9 October 2021 / Published online: 23 October 2021

(C) The Author(s), under exclusive licence to Springer Nature B.V. 2021

\begin{abstract}
Community geography emphasizes the centrality of community engagement to socially transformative research. This introduction to a special issue of GeoJournal on community geography outlines how this growing subfield provides a model for collaborative action with the crises of our time, from white supremacy through climate change. As the coeditors of this special issue, we summarize the contents of these 14 articles, grouping them by the shared themes of power, institutional partnerships, pedagogy, and methods.
\end{abstract}

Keywords Community geography $\cdot$ Community engagement $\cdot$ Participatory research

\footnotetext{
J. Shannon ( $($ )

University of Georgia, Athens, GA, USA

e-mail: jshannon@uga.edu

H. Torres

University of New Mexico, Albuquerque,

NM, USA

K. A. Mariner

University of Rochester, Rochester, NY, USA

T. L. Hawthorne

University of Central Florida, Orlando,

FL, USA

e-mail: timothy.hawthorne@ucf.edu
}

\section{Introduction}

The first community geography program was created at Syracuse University in 2005, headed by Jonnell Robinson (2010). Since that time, community geography programs have been created at several other American universities, including University of Central Florida, Columbus State University, University of Georgia, University of New Mexico, and Kent State University. The focus of community geography has been on developing models for research and teaching that actively extend beyond the academy, with a goal of producing "mutually beneficial and co-produced knowledge" (Shannon et al., 2020, p. 1). Community geography draws from previous work in participatory research methodologies that emphasize reflexivity and the co-production of knowledge (Mason, 2015), as well as a feminist insistence on the situated nature of knowledge (Haraway, 1988). Most significantly, community geography gives attention to methods for building partnerships and the development of institutional models that explicitly value the expertise and needs of public scholars.

Rooted partly in the tradition of American pragmatism, community geographers use research as a form of organizing. Rejecting a top-down model that privileges the university as a site of theorization and knowledge production, this tradition emphasizes the centrality of active collaboration around collectively identified problems for socially transformative research. As Wills and Lake describe it, "Such 
research is designed to be useful: in the language of pragmatism, it is about working with publics around their problems in community-based inquiry and, in the process, further building the collective capacity to act" (Wills \& Lake, 2020, p. 5). While Dewey and other early pragmatists are sometimes critiqued for a perceived discursive focus that fails to consider the power dynamics shaping public engagement, later authors have underscored the political and moral aspects of pragmatist work. Cornel West (1989), for example, posits a prophetic pragmatism that "puts a premium on educating and being educated by struggling peoples, organizing and being organized by resisting groups" (p. 234), noting that this work opposes "all those power structures that lack public accountability" (p. 235). In a similar way, Forester writes how critical pragmatism "directs our attention not only to moves and consequences and our orienting theories, but to the political and moral conditions of our deliberations in the first place" (Forester, 2013, p. 19).

This focus on the institutional contexts of our work fits alongside other ongoing disciplinary transformations within geography. These include increasing awareness of the pervasive whiteness of the discipline and the welcome growth of Black, Latinx, and Indigenous Geographies (Ducre, 2018; Eaves, 2017; Faria et al., 2019). Within the United States, where most community geography programs are currently found, recent research has highlighted the settler colonialist histories of land grant universities and their reliance on past practices of enslavement, displacement, and genocide (Lee \& Ahtone, 2020; Wilder, 2014). Community geography supports and intersects with the work of scholars in these areas, building models of research and teaching that are reciprocally beneficial rather than extractive.

These concerns are, of course, not limited strictly to academia, as evidenced by the multiple crises of our current moment: ongoing climate change, uprisings for racial justice and resurgent white nationalism, antiimmigrant violence and xenophobia, and the global COVID-19 pandemic. While these challenges may often feel overwhelming, the articles in this special issue illustrate how community geography provides one framework for our collective efforts to build a more equitable and sustainable future. To address our pressing challenges, community geographers both inside and outside the academy must facilitate public conversations, ensuring the presence of often excluded groups, being attentive to the power dynamics that shape community organizing, and building consensus around plans for future action. The articles in this special issue demonstrate that this is a subtle, difficult, and often times aspirational task, but also one that opens potential pathways for social change.

\section{Introduction to this issue: the relevance of community geography}

The articles in this special issue arose from a National Science Foundation-funded event, the National Workshop on Community Geography, held in January 2019. During the workshop, 41 sponsored fellows presented their work in an effort to better define an agenda for the development of community geography. The authors in this special issue were among those fellows, and so this special issue builds on the goals of that workshop. In addition, the newly formed Community Geographies Collaborative (cgcollaborative.org) will provide an ongoing forum for scholars doing communityengaged research and teaching to share work and connect with one another.

The fourteen articles included in this special issue address a range of issues both methodological and substantive. Many of these pieces directly address already mentioned crises. For example, Pablo Bose (2020) describes his work using photovoice with recent immigrants. His article outlines key ethical concerns of working with individuals who may be hesitant to become visible but also describes potential models for research that explicitly highlights experiences of xenophobia. Hemsworth and co-authors (2021) describe an initiative to repatriate Anishinaabe artifacts that grew out of a longer partnership between Indigenous and non-Indigenous communities. This partnership also seeks to re-center understanding of the Lake Nipissing region around Anishinaabe knowledge in the context of ongoing climate change. Kumaska and co-authors (2021) describe a similar partnership between universities and multiple Indigenous groups to develop new ideas for responding to the effects of climate change. Two other articles in this special issue identify ways that mapping and spatial analysis can be used to identify historical and current patterns of gentrification and displacement rooted in racialized urban geographies while also partnering 
with individuals and groups most affected by these issues (Ehrman-Solberg et al., 2020; Matsuoka \& Urquiza, 2021).

\section{Power in community geography research}

Several articles in this issue focus on the ethics of community-based research and the ways that power operates through both individual positionality and institutional contexts. This has been a primary focus of participatory and feminist research, as well as activist scholarship, and these articles build upon that past research. Barrett and Bosse (2021) offer a set of personal reflections rooted in two community geography case studies situating their own experiences as graduate students and thus precarious researchers. They ask community geographers to consider the ways that power dynamics between precarious researchers within the university and non-academics may question whether universities are by default the dominant institution in a partnership. Such a discussion is particularly salient as community geographers think about mutually beneficial ways to co-produce knowledge while recognizing the challenges for researchers who are in positions of precarity.

Mokos' (2021) article examines the methodological and ethical challenges of navigating disparate power relations in geography research. It does so by drawing from an intensive ethnographic account based on a year of fieldwork in Southern California and culminating with a description of an innovative performative ethnography workshop. An excellent example of relational ethnography (Desmond, 2014), Mokos' account carefully considers complex sets of competing interests held by residents of encampments on the Ventura River, environmental workers tasked with restoring the riverbottom, and social service workers attempting to more stably house riverbottom residents. The article provides an incisive interrogation of the power relations created through community engagement, environmental restoration, social work, and geographical research. An important contribution of this piece is Mokos' consideration of the researcher as a crucial actor in these relations, not simply a neutral observer. Through reflexive attention to relationships within this collective, Mokos' article demonstrates that "community" is a socially, historically, and culturally contingent signifier, imbricated in fraught relations of power.
Allahwala and colleagues (2021) consider the ways in which youth engagement and youth voices can be prioritized in community geography projects while discussing their three-year case study in a Toronto, Canada neighborhood. Their focus on youth priorities in neighborhood planning considers the complexities of power and ethics when centering youth voices in community geography work. Their focus on both narrative and critical reflection demonstrates how community geographers grapple with how to support both a youth-focused and youth-led process for community geography. They discuss the paid vs. volunteer status of youth engagement; the need to manage expectations of youth in the broader policy discussions; and how community geographers can value the lived experiences and knowledge of youth. They conclude by offering a series of key recommendations for youth-led and youth-focused community geography to ensure youth voices and knowledge are centered in these processes. This article thus suggests how youth might be more meaningfully included as full participants in community-based research.

\section{Institutional partnerships}

Although similar to other forms of participatory research, community geography is distinctive in the ways it has been institutionalized within American universities. The first community geography program was started at Syracuse University in 2005, and multiple programs have created positions with that title in recent years (Robinson \& Hawthorne, 2017; Robinson et al., 2016; Shannon et al., 2020). These positions entail a unique set of responsibilities, such as alternate teaching responsibilities or increased expectations for service. Attention to the institutional contexts of this work is thus a key area of focus for many of these articles, particularly the need to cultivate trust between partners and increase support and recognition for engaged research within academic institutions.

In their article, Matsuoka and Urquiza (2021) describe a set of research projects created by the Northeast Los Angeles Alliance, a group of local residents who, in partnership with Occidental College, have used mapping to track ongoing gentrification and residential displacement in their area. These projects have included identifying patterns of displacement, parcel vulnerability, and a dashboard to provide better 
access to property data. The results of this research have been useful for community activism, providing "a mirror for the community to see itself." At the same time, this work was also "an important method for building trust and relationship within and across communities." According to the authors, collectives focused on community mapping should be treated as community-based organizations within research on social activism, as a forum for building connections and power to resist processes of economic extraction.

Similarly, Ehrman-Solberg and co-authors (2020) describe the process of community engagement for Mapping Prejudice, a research project that maps the history of racially restrictive covenants for homes in Minneapolis, Minnesota and another collaborative project called CREATE. Collaboration in the Mapping Prejudice project happens on multiple scales, from a crowdsourced platform to digitize historical records through shared strategies for publishing data and findings. Based on these experiences, the authors emphasize the relational work of nurturing these partnerships, including understanding how research fits within the local history of a place (doing research "in" place rather than "about" place), using an iterative process of research design, and regular reflexive attention to the health of partnerships. Mapping Prejudice is notable for its use of new tools for document scanning and community input, but this article underscores how these methodological innovations were supported by intentionally cultivated relationships with community groups and residents.

In another article focused on articulating and redressing historical dispossession, Hemsworth and colleagues (2021) discuss a place-based reparative partnership between Nbisiing Anishinaabeg communities, northern Ontario, Canada universities, and multi-scalar museums. They discuss how community geographers can better support Indigenous knowledge in community partnerships, recognizing that such knowledge existed long before geography became a discipline. Their focus on "community geographies of repair" in partnerships with Indigenous communities makes an important point: "the power of settler colonialism is that it has normalized colonial knowledge systems (and, in doing so, dispossessed Indigenous knowledges) to such an extent that it is not always immediately clear that repair is needed, or the type of reparation required. Sometimes, the reparatory process can only become more evident after collectively exposing and dismantling an oppressive system-a task BIPOC scholars and communities have carried on their own for too long." The authors note that Indigenous access to resources and funding to engage in repair and repatriation work is but one component of the community geography process, and they caution that such processes are often rooted in deep emotion and trauma as such histories and knowledge are shared by Indigenous communities in the research process. They rightfully ask community geographers to learn and work with Indigenous community partners, rather than to speak for them, while arguing for a more compassionate place-based approach to the community geographies of repair and repatriation with Indigenous communities.

Kumasaka et al. (2021) also interrogate the power dynamics inherent in research for, by, and with indigenous communities in the context of planning for climate-driven relocation. By sharing the processes and outcomes of a two-way workshop with members from the Biloxi-Chitimacha-Choctaw Tribe from Isle de Jean Charles in Louisiana, Yup'ik people from Newtok Village in Alaska, and researchers from the MIT Resilient Communities Lab, the authors seek to advance a participatory practice model for joint knowledge production that emphasizes openness, flexibility, and responsiveness. The paper explores a number of challenges and opportunities for forming academic and Indigenous community partnerships before suggesting critical future directions to support integrating traditional knowledge into pedagogy, discourse and practice of academic planning programs.

In another piece focused on engagements with youth, Guhlincozzi and Cisneros (2021) describe their work developing G-Camp, a summer program focused on geoscience education targeting middle school-aged girls of color. As graduate students, the authors worked closely with a community partner to design the camp and coordinate outreach, and the initial version of the camp was largely successful. Yet as the paper outlines, a long-term partnership between the university and community partner proved untenable. Through active reflection on their experience and an analysis of the motivations and goals of each partner, the authors highlight how the institutional incentives of the university worked against creating long-term trusting partnerships, even as those partnerships met stated priorities for diversity and inclusion. As they 
write, "Despite the fact that SESE claims to support community outreach, it was unwilling to take the necessary steps and devote resources to make the camp outreach a priority, even when provided with the opportunity to do so." Similar to Barrett and Bosse, these two authors are especially attentive to their position as graduate students within the university and their limited capacity to influence faculty and institutional decisions.

Lastly, as essential reading for those new to community geography, the article in this volume by Fischer et al. (2021) situates contemporary community geography within a longer tradition of participatory and applied geography, and offers a practical guide specifically aimed at university researchers interested in creating institutional/community partnerships and projects. This piece builds on two earlier publications on theory (Shannon et al., 2020) and pedagogy in community geography (Rees et al., 2020). Fischer et al. break down the actors, motivations, and methods that structure community geography praxis, offering numerous rich and illuminating examples of ways that existing higher education institutions and community geographers have built infrastructure to support these projects and partnerships. The authors also outline a number of potential challenges and ethical issues central to community geography that are crucial for practitioners to consider.

\section{Pedagogy}

Other papers in this special issue focus on classroom spaces, both inside and outside the university. In line with past work on action or service-learning, these papers outline how the process of engagement recenters instruction by drawing attention to the ways geographic knowledge is implemented and the institutional context of community partnerships. The article by Guhlincozzi and Cisernros, described above, is one example of a summer program developed for middle-school students aimed at increasing gender and racial diversity within the geosciences.

By providing multiple case studies from the university classroom, Amy Rock's (2021) article in this issue reflects community-based learning, describing how courses developed a sense of "spatial citizenship" for students. Rock provides multiple models for how these courses can be designed and implemented with a variety of community partners. As others have also noted (Robinson et al., 2016), Rock emphasizes the need for community geographers to be both embedded in place and highly adaptable when developing class experiences. While this work is challenging, it allows students to "become stakeholders in [locally relevant] issues, rather than passive observers, and that understanding carries forward into more engaged citizenship throughout their lives." This article provides a practical guide for those seeking to implement community geography within the classroom.

Considering a project in Illinois, James et al. (2021) provide a compelling account of a communityengaged project that transitioned from a servicelearning model to a community geography framework. One critique of service-learning courses is that they can privilege pedagogical interests over community needs. The specific project described by James et al.the planning of a university/community research and outreach center-attempts to address this imbalance. The authors describe how the traditional planning approach initially utilized by the service-learning course, which was designed to solicit input from residents, overlooked important issues relevant to the surrounding community. A community geography framework facilitated a number of important shifts and insights in how the project was conceptualized and carried out: a turn from 'looking at' or 'working in' to 'working with,' attention to the importance of shared experiences and co-production of knowledge, modes of building trusting relationships, and strategies for reconciling competing visions and goals. The authors include an account of initial student reluctance or hesitation with respect to the transition from servicelearning to community geography, an important contribution for others interested in replicating similar projects and interventions that weave research and pedagogy to mobilize university resources toward community interests. Importantly, this article provides a number of helpful strategies and methodological considerations for geographers considering community-engaged projects.

Methods and tools

Other articles in this special issue address methodological concerns and approaches, highlighting strategies for inclusive research. In a reflexive account of using community geography to examine the 
experience of refugee resettlement in Vermont, Pablo Bose (2020) touches upon many of the ethical quandaries raised by other writers in this collection. The use of photovoice as a participatory method sets this piece apart as an insightful exploration of the relationship between method, ethics, and an increasingly polarized political climate. As Bose illustrates, the visual politics of photovoice amplify the participatory values and epistemological stakes of community geography, by challenging hegemonic notions of power and knowledge-but these visual politics also introduce logistical challenges and vulnerabilities. This article poses several provocative and important questions for researchers to consider, interrogating the relationship between reciprocity, positionality, collaboration, inequality, and expectations. Compellingly animated by the words of refugee interlocutors, Bose's account probes the ethics of doing community-based work with marginalized subjects, particularly in times of heightened xenophobia.

Drawing on a sample of nine participatory research projects over fourteen years, Cumming et al. (2021) evaluate the Community Voice Method (CVM) as an approach to account for the knowledge, values and views of community stakeholders in natural resource management decisions. Developed by the authors as an alternative stakeholder engagement process, CVM is a mixed-method, iterative technique in which stakeholders are interviewed and the interview data is presented through documentary films that are publicly screened to catalyze dialogue about natural resource concerns and/or conflicts. In their paper, the authors review CVM project participant feedback and use participant observation to reflect on CVM through the lens of community geography. Through illustrative case studies from Carteret County, NC, Turks and Caicos, and East Anglia (UK), the authors argue that the CVM approach facilitates stakeholder engagement processes that are perceived as trustworthy, relevant, representative, and productive.

\section{Concluding thoughts}

In a period of compounding crises, community geography is a developing model of engaged scholarship that critically rethinks the conditions in which knowledge is produced and shared. While academic institutions have a role to play in tackling the ongoing
COVID19 pandemic, addressing the threats of climate change, and challenging the persistence of white nationalism and settler colonial practices, the increasing skepticism of academic expertise by large segments of the public demonstrates that published research alone is insufficient. As these articles illustrate, a community geography approach emphasizes innovative models of scholarship that explicitly recognize and incentivize collaborative partnerships. These build trust and relationship between partners and facilitate a praxis between research and social action. This work is not easy, requiring thoughtful attention to power dynamics within partnerships and taking time to thoughtfully construct models for partnerships that are mutually beneficial across often significantly different institutional contexts. Still, by giving attention to this necessary relational and institutional labor, scholars in community geography can build more durable frameworks for collaboratively addressing the crises of our time.

\section{References}

Allahwala, A., \& Bhatia, A. (2021). Supporting youth-led community geography on the impacts of neighbourhood social infrastructure on young people's lives: A case study from East Scarborough, Canada. GeoJournal.

Barrett, E., \& Bosse, A. J. (2021). Community geography for precarious researchers: Examining the intricacies of mutually beneficial and co- produced knowledge. GeoJournal. https://doi.org/10.1007/s10708-020-10358-2

Bose, P. S. (2020). Refugee research in the shadow of fear. GeoJournal, 0123456789,. https://doi.org/10.1007/ s10708-020-10342-w

Cumming, G., Campbell, L., Norwood, C., Ranger, S., Richardson, P., \& Sanghera, A. (2021). Putting stakeholder engagement in its place: How situating public participation in community improves natural resource management outcomes. GeoJournal, 1. https://doi.org/10.1007/s10708020-10367-1

Desmond, M. (2014). Relational ethnography. Theory and Society, 43(5), 547-579. https://doi.org/10.1007/s11186$014-9232-5$

Ducre, K. A. (2018). The black feminist spatial imagination and an intersectional environmental justice. Environmental Sociology, 4(1), 22-35.

Eaves, L. E. (2017). Black geographic possibilities. Southeastern Geographer, 57(1), 80-95.

Ehrman-Solberg, K., Keeler, B., Derickson, K., \& Delegard, K. (2020). Mapping a path towards equity: Reflections on a co-creative community praxis. GeoJournal, 1. https://doi. org/10.1007/s10708-020-10294-1. 
Faria, C., Falola, B., Henderson, J., \& Maria Torres, R. (2019). A long way to go: Collective paths to racial justice in geography. Professional Geographer, 71(2), 364-376. https://doi.org/10.1080/00330124.2018.1547977

Fischer, H., Block, D., Bosse, A., Hawthorne, T. L., Jung, J.-K., Pearsall, H., Rees, A., \& Shannon, J. (2021). Doing community geography. GeoJournal. https://doi.org/10.1007/ s10708-021-10457-8

Forester, J. (2013). On the theory and practice of critical pragmatism: Deliberative practice and creative negotiations. Planning Theory, 12(1), 5-22. https://doi.org/10.1177/ 1473095212448750

Guhlincozzi, A., \& Cisneros, J. (2021). A framework for addressing the lack of diversity in the Geosciences through evaluating the current structure of institutional efforts. GeoJournal. https://doi.org/10.1007/s10708-021-10418-1

Haraway, D. (1988). Situated knowledges: The science question in feminism and the privilege of partial perspective. Feminist Studies, 14(3), 575-599.

Hemsworth, K., Greer, K., Paulin, M., \& Sutherland, K. (2021). Maada ' oonidiwag gete-dibaajimowen (" " sharing old stories "'): Reflections on a place-based reparatory research partnership in Nbisiing Anishinaabeg Territory. GeoJournal, 3. https://doi.org/10.1007/s10708-02110432-3

James, A. C., Alyasiri, E., Howe, M., James, R. D., Jin, Y., Lwanga, K., McClain, B., Moore, A., Shao, Y., \& Valdez, F. (2021). Broadening participation, creating community, and learning that it never goes as planned. GeoJournal. https://doi.org/10.1007/s10708-021-10442-1

Kumaska, O., Bronen, R., Harrington, E., Knox-Hayes, J., Laska, S., Naquin, A., Patrick, A., Peterson, K., \& Stanley, T. (2021). Planning for resettlement: Building partnerships for, by, and with indigenous peoples. GeoJournal.

Lee, R., \& Ahtone, T. (2020). Land-grab universities. Retrieved from https://www.hon.org/issues/52.4/indigenous-affairseducation-land-grab-universities

Mason, K. (2015). Participatory action research: Coproduction. Governance and Care. Geography Compass, 9(9), 497-507. https://doi.org/10.1111/gec3.12227

Matsuoka, M., \& Urquiza, J. (2021). Building community knowledge, resilience and resistance through research. GeoJournal, 5. https://doi.org/10.1007/s10708-02110422-5
Mokos, J. T. (2021). Engaging the complexities of community: Conflict and difference in community-engaged research. GeoJournal, 3. https://doi.org/10.1007/s10708-02110397-3

Rees, A., Hawthorne, T., Scott, D., Solís, P., \& Spears, E. (2020). Toward a community geography pedagogy: A focus on reciprocal relationships and reflection. Journal of Geography. https://doi.org/10.1080/00221341.2020. 1841820

Robinson, J. A., \& Hawthorne, T. L. (2017). Making space for community-engaged scholarship in geography. The Professional Geographer, 70(2), 277-283. https://doi.org/10. 1080/00330124.2017.1366775

Robinson, J. A., Block, D., \& Rees, A. (2016). Community geography: Addressing barriers in public participation GIS. The Cartographic Journal, 54(1), 5-13. https://doi. org/10.1080/00087041.2016.1244322

Robinson, J. A. (2010). Syracuse community geography: evaluating a new approach to public participation geographic information systems. University of North Carolina.

Rock, A. E. (2021). Bringing geography to the community: Community-based learning and the geography classroom. GeoJournal, 3. https://doi.org/10.1007/s10708-02110408-3

Shannon, J., Hankins, K., Shelton, T., Bosse, A., Scott, D., Block, D., Fischer, H., Eaves, L. T. E., Jung, J. K., Robinson, J., Solís, P., Pearsall, H., Rees, A., \& Nicolas, A. (2020). Community geography: Toward a disciplinary framework. Progress in Human Geography. https://doi. org/10.1177/0309132520961468

West, C. (1989). The American evasion of philosophy: A genealogy of pragmatism. Macmillan.

Wilder, C. S. (2014). Ebony and ivy: Race, slavery, and the troubled history of America's universities. Bloomsbury Publishing.

Wills, J., \& Lake, R. W. (2020). Introduction: The power of pragmatism. In J. Wills \& R. W. Lake (Eds.), The power of pragmatism (pp. 3-52). Manchester University Press.

Publisher's Note Springer Nature remains neutral with regard to jurisdictional claims in published maps and institutional affiliations. 